\title{
Crustal attenuation characteristics of S-waves beneath the Eastern Tohoku region, Japan
}

\author{
Muhammad Adeel Arshad
}

Received: 9 January 2016/ Accepted: 8 May 2016/Published online: 21 October 2016

(c) The Author(s) 2016. This article is published with open access at Springerlink.com

\begin{abstract}
An inversion method was applied to crustal earthquakes dataset to find S-wave attenuation characteristics beneath the Eastern Tohoku region of Japan. Accelerograms from 85 shallow crustal earthquakes up to $25 \mathrm{~km}$ depth and magnitude range between 3.5 and 5.5 were analyzed to estimate the seismic quality factor $Q_{\mathrm{s}}$. A homogeneous attenuation model $Q_{\mathrm{s}}$ for the wave propagation path was evaluated from spectral amplitudes, at 24 different frequencies between 0.5 and $20 \mathrm{~Hz}$ by using generalized inversion technique. To do this, non-parametric attenuation functions were calculated to observe spectral amplitude decay with hypocentral distance. Then, these functions were parameterized to estimate $Q_{\mathrm{s}}$. It was found that in Eastern Tohoku region, the $Q_{\mathrm{s}}$ frequency dependence can be approximated with the function $33 f^{1.22}$ within a frequency range between 0.5 and $20 \mathrm{~Hz}$. However, the frequency dependence of $Q_{\mathrm{s}}$ in the frequency range between 0.5 and $6 \mathrm{~Hz}$ is best approximated by $Q_{\mathrm{s}}(f)=36$ $f^{0.94}$ showing relatively weaker frequency dependence as compared to the relation $Q_{\mathrm{s}}(f)=6 f^{2.09}$ for the frequency range between 6 and $15 \mathrm{~Hz}$. These results could be used to estimate source and site parameters for seismic hazard assessment in the region.
\end{abstract}

Keywords Tohoku - Generalized inversion technique . Non-parametric attenuation function - Seismic quality factor $\cdot \mathrm{S}$-wave

M. A. Arshad ( $\square)$

Department of Civil Engineering, University of Engineering \&

Technology, Peshawar, Peshawar 25120, KPK, Pakistan

e-mail: ceadeel@uetpeshawar.edu.pk

\section{Introduction}

The study region is confined within $38^{\circ} \mathrm{N}$ to $39.5^{\circ} \mathrm{N}$ and $140.5^{\circ} \mathrm{E}$ to $142.5^{\circ} \mathrm{E}$, and contains eastern part of Tohoku region in Japan's Honshu Island as shown in Fig. 1. Eastern Tohoku mainly comprises Iwate and Miyagi prefectures. The region is situated over one of the most active tectonic regimes of the world where Pacific plate is subducting under the Eurasian plate, generating numerous earthquakes in this area.

There is a close connection between the topography of the Tohoku region and the distribution of active faults. The topography of the Tohoku region is characterized by alternate mountain ranges and lowlands running in a northsouth direction. The primary active faults of the Tohoku region lie at the boundaries of the mountains and the lowlands.

The crustal depth beneath Tohoku is estimated to be 25-30 km (Kaminuma and Aki 1963; Zhao et al. 1992) and many of the large destructive inland earthquakes are known to have occurred at these shallower depths. The shallower crustal earthquakes tend to result in a greater intensity of surface shaking and often cause the greatest loss of life and damage to property. In engineering applications like seismic hazard analysis, S-wave phases of ground motions are of most interest, as most of the seismic energy from the earthquake source is radiated in the form of S-waves. Therefore, quantification of the S-wave attenuation characteristics is necessary.

The records of strong earthquakes can be inverted to obtain the characteristics of attenuation, radiation and propagation pattern of seismic waves and to construct models of ground behaviour at various stations (Pavlenko and Wen 2008). In this study, linear inversion analysis following a non-parametric approach has been performed 


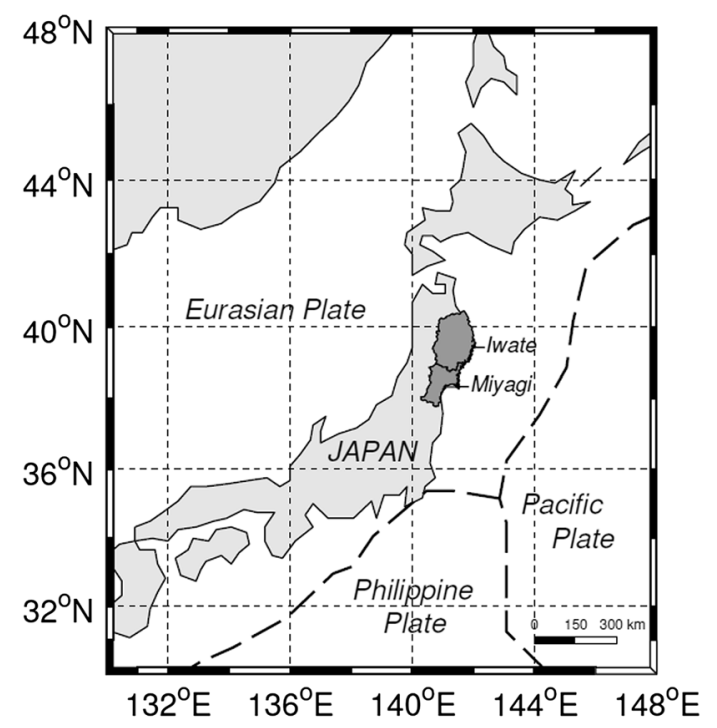

Fig. 1 Map of Japan showing Iwate and Miyagi prefectures which constitute Eastern Tohoku

to investigate the frequency dependence of attenuation of S-waves $\left(Q_{\mathrm{s}}\right)$.

\section{Dataset}

The dataset comprises 315 three-component earthquake records, from 85 earthquakes recorded at 6 K-NET (Kyoshin network) stations installed in the Eastern Tohoku region of Japan in the framework of National Research Institute for Earth Science and Disaster Prevention (NIED). The earthquake records were obtained over a period of nine years from Dec-2003 to May-2012 with magnitudes $M_{\mathrm{w}}$ ranging between 3.5 and 5.5 and hypocentral distances between 35 and $125 \mathrm{~km}$. The data have been sampled at $100 \mathrm{~Hz}$. The data represent no distance dependence in magnitude as shown in Fig. 2.

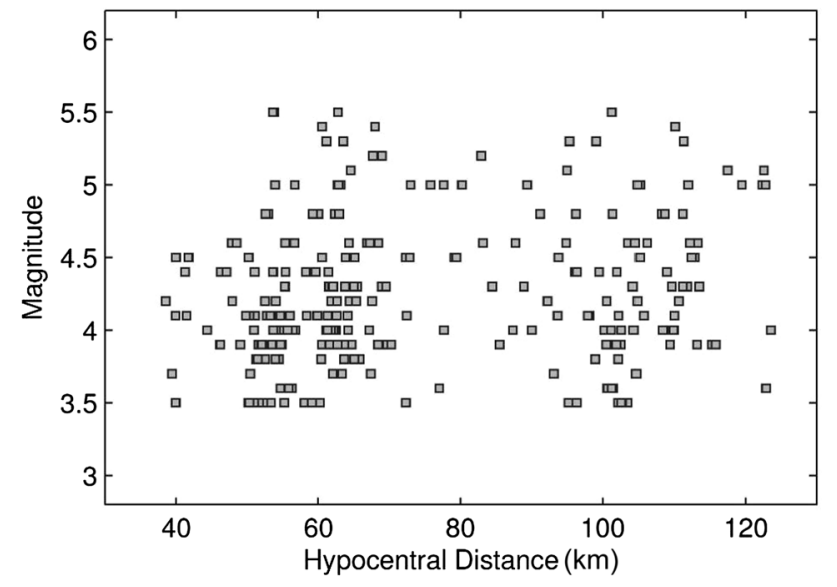

Fig. 2 Distribution of magnitudes with hypocentral distances
The site details of the K-NET stations used in this study are listed in Table 1. These stations were initially installed with K-NET95-type accelerometers which were later replaced with K-NET02-type accelerometers in 2004 (Okada et al. 2004). Since, the crustal thickness of Eastern Tohoku region ranges in between 25 to $30 \mathrm{~km}$, the hypocentral depth of the selected events was restricted not to exceed $25 \mathrm{~km}$. Moreover, only those earthquakes were selected which were recorded by at least three stations. The details of epicentral coordinates of the events used and the hypocentral distances to the recording stations are provided in Appendix Table 2. The ray paths between different source-station pairs in the region are shown in Fig. 3. There are many crossing ray paths between different source station pairs ensuring reliable estimates of homogeneous attenuation model.

\section{Data processing and analysis}

The records were corrected for instrumental response and baseline. Instrument correction was only applied on the records from K-NET95-type accelerometers for frequencies larger than $\sim 15 \mathrm{~Hz}$, as the response of these accelerometers slightly decrease for frequencies larger than this limit. The baseline was corrected by subtracting the average of all the points of the record. S-wave portion of both the horizontal components of the recorded accelerograms were analyzed. For each horizontal component of the records, the $\mathrm{S}$-wave window was selected such that it starts $1 \mathrm{~s}$ before the $\mathrm{S}$-wave onset and ends when $80 \%$ of the total energy of the record is reached as shown in Fig. 4. Typical window lengths range between 5 and $12 \mathrm{~s}$. If in any case the window's length increases over $20 \mathrm{~s}$, it was fixed to a maximum duration of $20 \mathrm{~s}$ to avoid having too much coda energy in the analyzed time window (Oth et al. 2011). The beginning and the end of S-wave window were tapered with a $5 \%$ cosine taper.

A plot showing the build-up of Arias intensity with time is known as a Husid plot (Fig. 4) and it serves to identify the interval with the arrival of majority of the energy.

The Fourier amplitude spectra (FAS) were computed for each window and smoothed around 24 frequency points equidistant on logarithmic scale between 0.5 and $20 \mathrm{~Hz}$ using the running mean filter. This smoothing technique is optimal for reducing random noise while keeping the sharpest step response (Smith 1999). The smoothing bandwidth is determined by trial-and-error. Having tested various smoothing bandwidths, the following criteria were adopted: for each frequency point, a bandwidth equal to 0.3 of an octave was considered; if this bandwidth was smaller than $0.5 \mathrm{~Hz}$, then $0.5 \mathrm{~Hz}$ was used as the smoothing 
Table 1 Location of the seismic stations used in this study

\begin{tabular}{llllcl}
\hline Site code & Site name & Lat. $\left({ }^{\circ}\right)$ & Long. $\left({ }^{\circ}\right)$ & Elevation $(\mathrm{m})$ & Station \\
\hline IWT007 & KAMAISHI & 39.270 & 141.856 & 11 & K-NET \\
MYG002 & UTATSU & 38.726 & 141.511 & 79 & K-NET \\
MYG003 & TOHWA & 38.735 & 141.311 & 28 & K-NET \\
MYG004 & TSUKIDATE & 38.729 & 141.022 & 40 & K-NET \\
MYG005 & NARUKO & 38.796 & 140.654 & 300 & K-NET \\
MYG011 & OSHIKA & 38.297 & 141.504 & 13 & K-NET \\
\hline
\end{tabular}

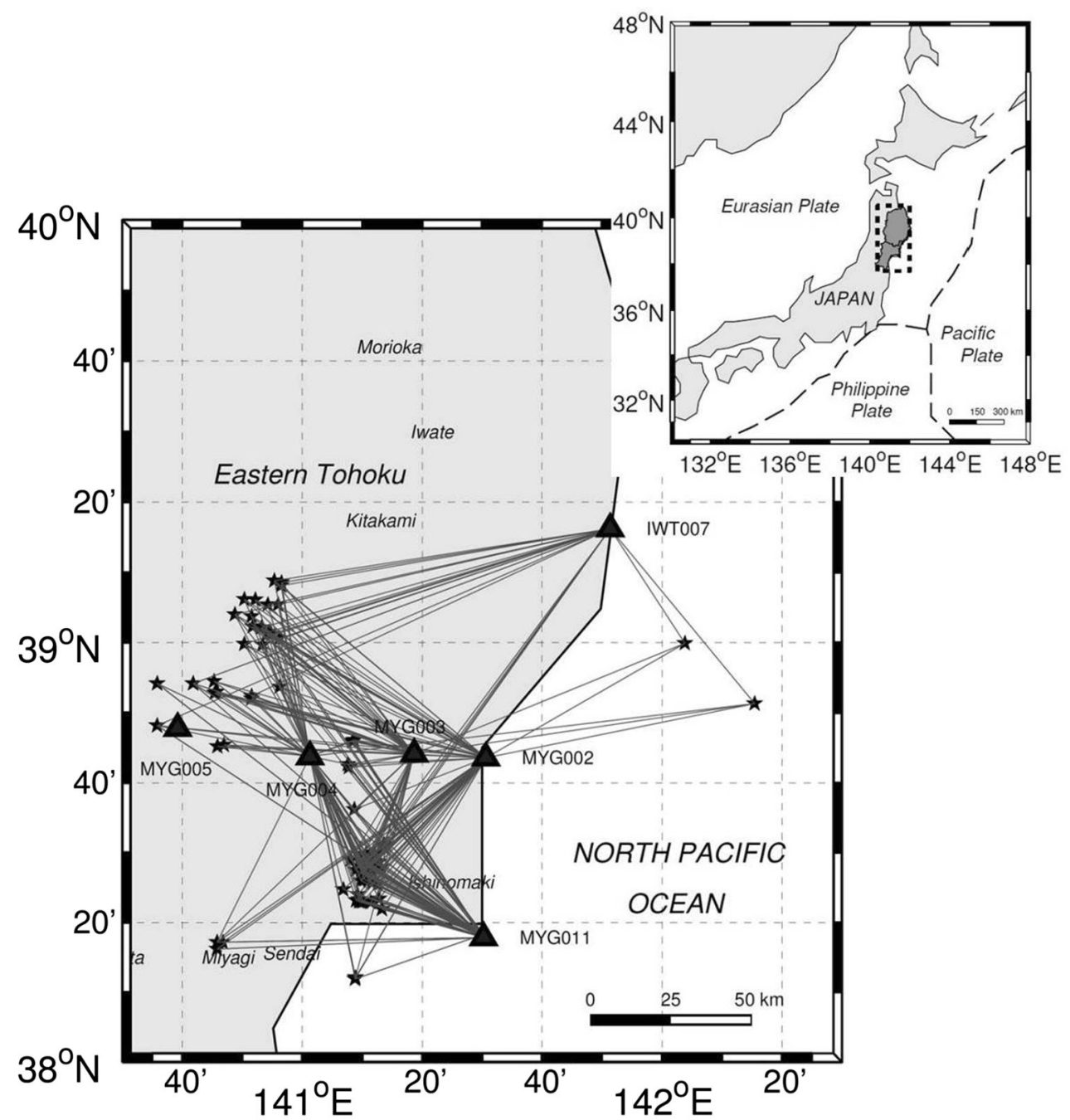

Fig. 3 Map of the Eastern Tohoku region that showing the distribution of the epicentres (stars) and the stations (triangles)

bandwidth. The signals to be analyzed have to satisfy stringent signal-to-noise ratio (SNR) requirements. Only data points with SNR greater than three were included in the final dataset. Figure 5 shows the raw and smoothed FAS of the chosen S-wave window from an accelerogram recorded at station IWT007. At lower frequencies, the database is slightly sparser due to SNR constraints as shown in Fig. 6.

\section{Method}

The generalized inversion technique (GIT) has been widely applied to crustal earthquake datasets (Andrews 1986; Castro et al. 1990). As a result of inversion, the frequency dependence of the attenuation of seismic waves as well as source characteristics and site response can easily be found (Parolai et al. 2000; Bindi et al. 2006). 

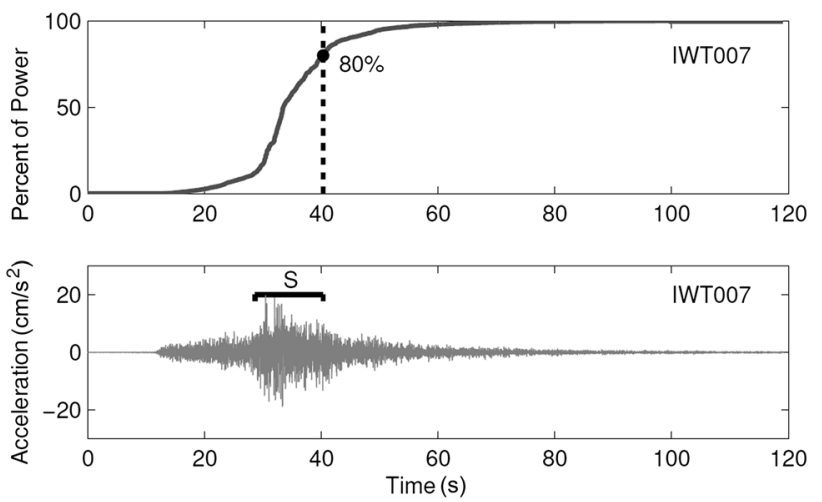

Fig. 4 Accelerogram of one of the earthquakes recorded at the station IWT007 (lower panel), highlighting the S-wave duration and the corresponding Husid plot (upper panel)

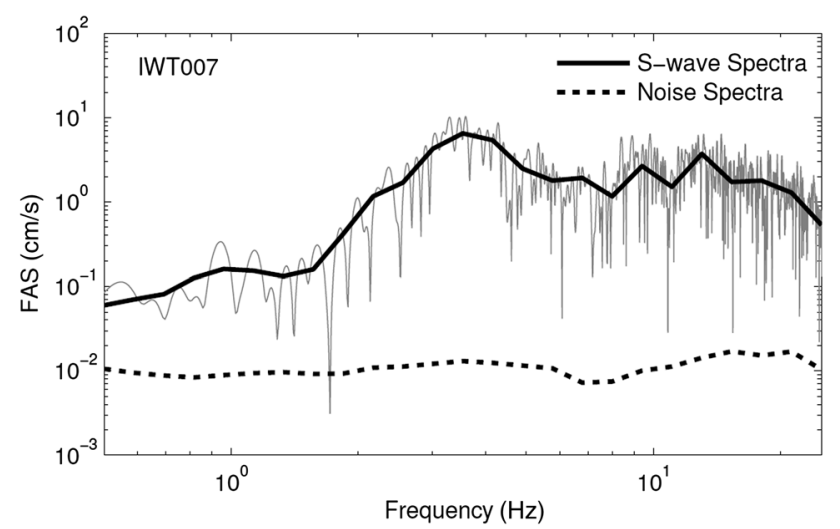

Fig. 5 Fourier amplitude spectrum (FAS) of the selected S-wave window from an accelerogram recorded at station IWT007. Raw and smoothed acceleration spectrums are shown by solid grey and solid black lines, respectively. Noise spectrum (dashed black line) is also shown for the same event to illustrate signal to noise levels
These dataset from Eastern Tohoku region allows us to make stable and reliable estimates of attenuation properties as it covers a reasonable range of magnitudes, distances and focal depths. Moreover, each event in the dataset was recorded by at least three stations, creating multiple crossing ray paths from sources to stations. Under these conditions, the effect of in-homogeneities in whole-path attenuation is thought to be effectively averaged out and GIT could successfully be applied to our dataset.

In this study, a non-parametric approach was employed (Castro et al. 1990), which considers attenuation phenomenon to be a smooth function, decreasing with distance. In non-parametric approach, the inversion is performed in two steps. Since, the attenuation characteristics $\hat{A}_{i j}\left(f, r_{i j}\right)$ are determined from the first step, we restrict the procedure to the first step of inversion. However, a subsequent inversion can be performed to separate source and site effects (Andrews 1986; Oth et al. 2009).

\subsection{Non-parametric approach}

The dependence of the spectral amplitudes $U(f, r)$ at frequency $f$ and on distance $r$ may be written as

$U_{i j}\left(f, r_{i j}\right)=\hat{A}_{i j}\left(f, r_{i j}\right) \cdot \hat{S}_{i}(f)$,

where $U_{i j}\left(f, r_{i j}\right)$ is the spectral amplitude (acceleration) from the $i$ th earthquake at the $j$ th station resulting, $r_{i j}$ is the source-site distance, the non-parametric attenuation function (NAF) $\hat{A}_{i j}\left(f, r_{i j}\right)$ describes seismic attenuation with distance, and $\hat{S}_{i}(f)$ is a scaling factor depending on the size of the $i$ th event. With this approach, the attenuation function remains independent of the size of an event. $\hat{A}_{i j}\left(f, r_{i j}\right)$ is not supposed to have any specific shape and implicitly

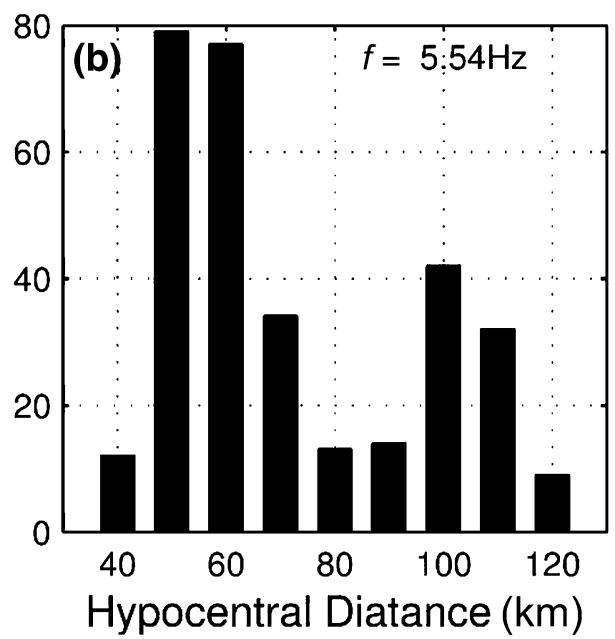

Fig. 6 Example of distribution of hypocentral distances at the two selected frequencies, 0.5 and $5.54 \mathrm{~Hz}$, respectively. At $0.5 \mathrm{~Hz}$, the database is slightly sparser than at $5.54 \mathrm{~Hz}$ due to signal-to-noise ratio constraints 
contains all effects leading to attenuation along the travel path (geometrical spreading, anelasticity, scattering, etc.). Based on the idea that these properties vary slowly with distance, $\hat{A}_{i j}\left(f, r_{i j}\right)$ is constrained to be a smooth function of distance i.e., with a small second derivative (Castro et al. 1990) and to take the value $\hat{A}_{i j}\left(f, r_{0}\right)=1$ at some reference distance $r_{0}$.

The representation given by Eq. (1) does not include a factor related to the site, and hence the site effects are necessarily absorbed both in $\hat{A}_{i j}\left(f, r_{i j}\right)$ and $\hat{S}_{i}(f)$. This is the reason that ' $\wedge$ ' is used to distinguish them from the 'uncontaminated' path and source terms $\hat{A}_{i j}\left(f, r_{i j}\right)$ and $S_{i}(f)$, respectively. $\hat{S}_{i}(f)$ contains, in fact, an average value of the site amplifications of all stations that recorded the $i$ th earthquake. Thus, $\hat{S}_{i}(f)$ is not the true source spectrum of the $i$ th event.

Equation (1) can be easily linearized by taking the logarithm:

$\log _{10} U_{i j}\left(f, r_{i j}\right)=\log _{10} \hat{A}_{i j}\left(f, r_{i j}\right)+\log _{10} \hat{S}_{i}(f)$.

Equation (2) represents an over-determined system of the form $\boldsymbol{A x}=\boldsymbol{b}$, where $\boldsymbol{b}$ is the data vector containing the logarithmic spectral amplitudes, $\boldsymbol{x}$ is the vector containing the model parameters, and $\boldsymbol{A}$ is the system matrix relating the two of them. The distance range was subdivided into nine distance bins $\left(N_{\mathrm{D}}\right)$, each $10 \mathrm{~km}$ wide, and the value of $\hat{A}_{i j}\left(f, r_{i j}\right)$ was computed in each bin. In matrix formulation, Eq. (2) takes the following form.
The left part of the system matrix in Eq. (3) contains the factors related to the attenuation parameters, whereas the right-hand side reflects those related to the source terms. The system matrix also includes rows relevant to constraints. The weighting factor $w_{1}$ is used to impose $\hat{A}_{i j}\left(f, r_{0}\right)=1$ at the reference distance $r_{0}$. Since the dataset contains most of the events with hypocentral distance greater than $40 \mathrm{~km}$, reference distance $r_{0}$ is set to $40 \mathrm{~km}$. By setting $\hat{A}_{i j}\left(f, r_{0}\right)=1$ at $r_{0}=40 \mathrm{~km}$ is, in fact, equal to assuming that there is no attenuation over that distance from the source. Hence, there is a cumulative attenuation effect over these $40 \mathrm{~km}$ that is impossible to resolve, and therefore, the $Q_{\mathrm{s}}$-model derived from the slopes of the attenuation functions, only reflects the attenuation characteristic over the remaining part of the travel path (i.e., more than $40 \mathrm{~km}$ away from the source). The weighing factor $w_{2}$ is implemented to achieve monotonically decaying attenuation curves with reasonable degree of smoothness to suppress the site-related effects and yet preserve variations of the attenuation characteristics with distance (Oth et al. 2009).

At each of the 24 selected frequencies, an inversion was performed in a least-square sense and a solution $x=\left(\boldsymbol{A}^{\mathrm{T}} \boldsymbol{A}\right)^{-1} \boldsymbol{A}^{\mathrm{T}} \boldsymbol{b}$ for a numerically stable system was computed (Menke 1989). As a result of successful inversion, the modal matrix gives the NAFs $\hat{A}_{i j}\left(f, r_{i j}\right)$ one for each bin and the values of $\hat{S}_{i}(f)$, one for each earthquake $i$. In this way, the unknown values which reduce the deviation between observations and model predictions can be

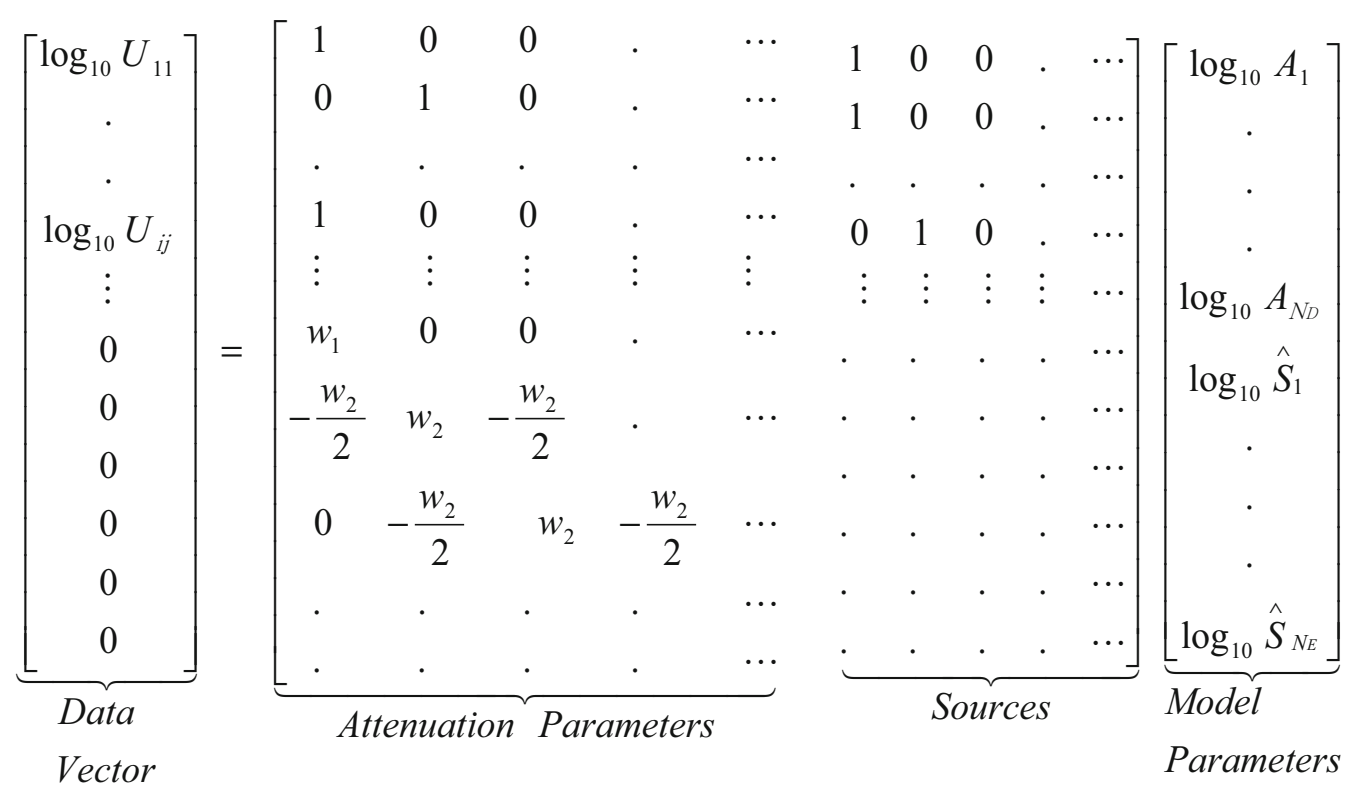



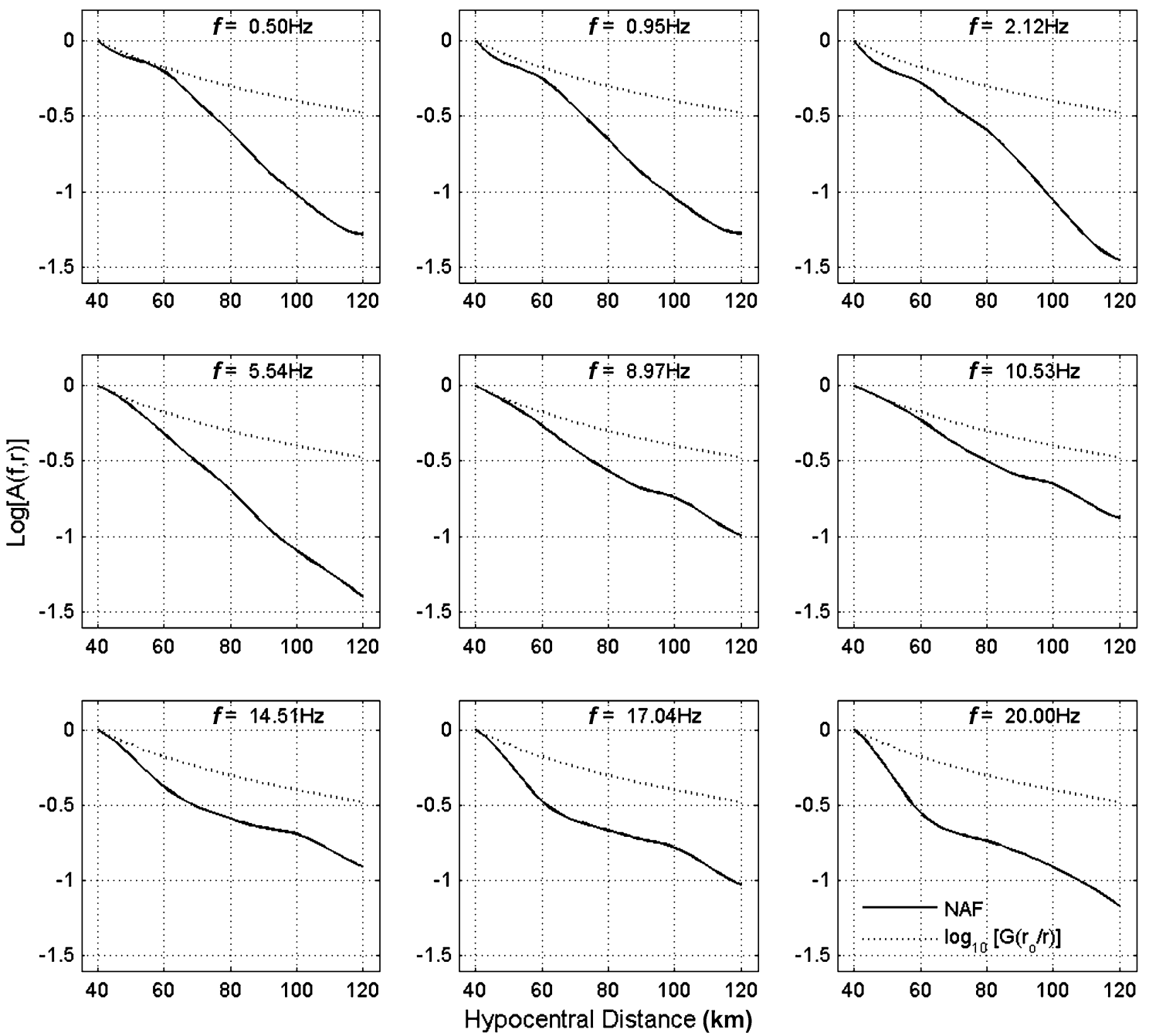

Fig. 7 Attenuation profiles observed at 9 of the 24 frequencies studied (solid lines) by fitting one function to the entire dataset (dashed lines). The functions are normalized to zero (in logarithm) at the reference distance $r_{0}$

evaluated in the form of sum of the squared residuals. The residual between the observed spectral amplitudes and those predicted by $U_{i j}\left(f, r_{i j}\right)=\hat{A}_{i j}\left(f, r_{i j}\right) \cdot \hat{S}_{i}(f)$, are interpreted as site effects. The attenuation curves evaluated at different frequencies are shown in Fig. 7.

\subsection{Seismic quality factor $\left(Q_{\mathrm{s}}\right)$}

The attenuation function $\hat{A}_{i j}\left(f, r_{i j}\right)$ combines the effect of the geometrical spreading and the anelastic attenuation in the same function. By using the non-parametric form of attenuation function, it becomes very easy to test it against any assumed geometrical spreading without repeating earlier computations.

The attenuation term $\hat{A}_{i j}\left(f, r_{i j}\right)$ can be parameterized in terms of frequency-dependent quality factor $Q_{\mathrm{s}}(f)$ and geometric spreading $G(r)$. Thus, we can express the attenuation function as
$\hat{A}_{i j}\left(f, r_{i j}\right)=G\left(r_{i j}\right) \cdot \exp \left(\frac{-\pi f r_{i j}}{Q_{\mathrm{s}}(f) \beta}\right)$.

The average $\mathrm{S}$-wave velocity $(\beta)$ estimated in the region is $3.2 \mathrm{~km} / \mathrm{s}$, measured from the S-P arrival times (Zhao et al. 1992; Kurahashi and Irikura 2011). The $Q_{\mathrm{s}}$ estimates are also sensitive to the choice of geometrical spreading function. Considering body wave propagation in an infinite homogeneous medium, the geometric spreading function $G$ ( $r$ ) was chosen to be $1 / r$. The amplitudes are normalized to $40 \mathrm{~km}$ as most of the observed spectral amplitudes start at $40 \mathrm{~km}$. Thus, for each frequency $f$, Eq. (4) is linearized correcting the empirical attenuation functions by the effect of geometrical spreading $G(r)=40 / r_{i j}$ and taking the logarithm. Thus, Eq. (4) is written as

$a(r)=-m r$, 

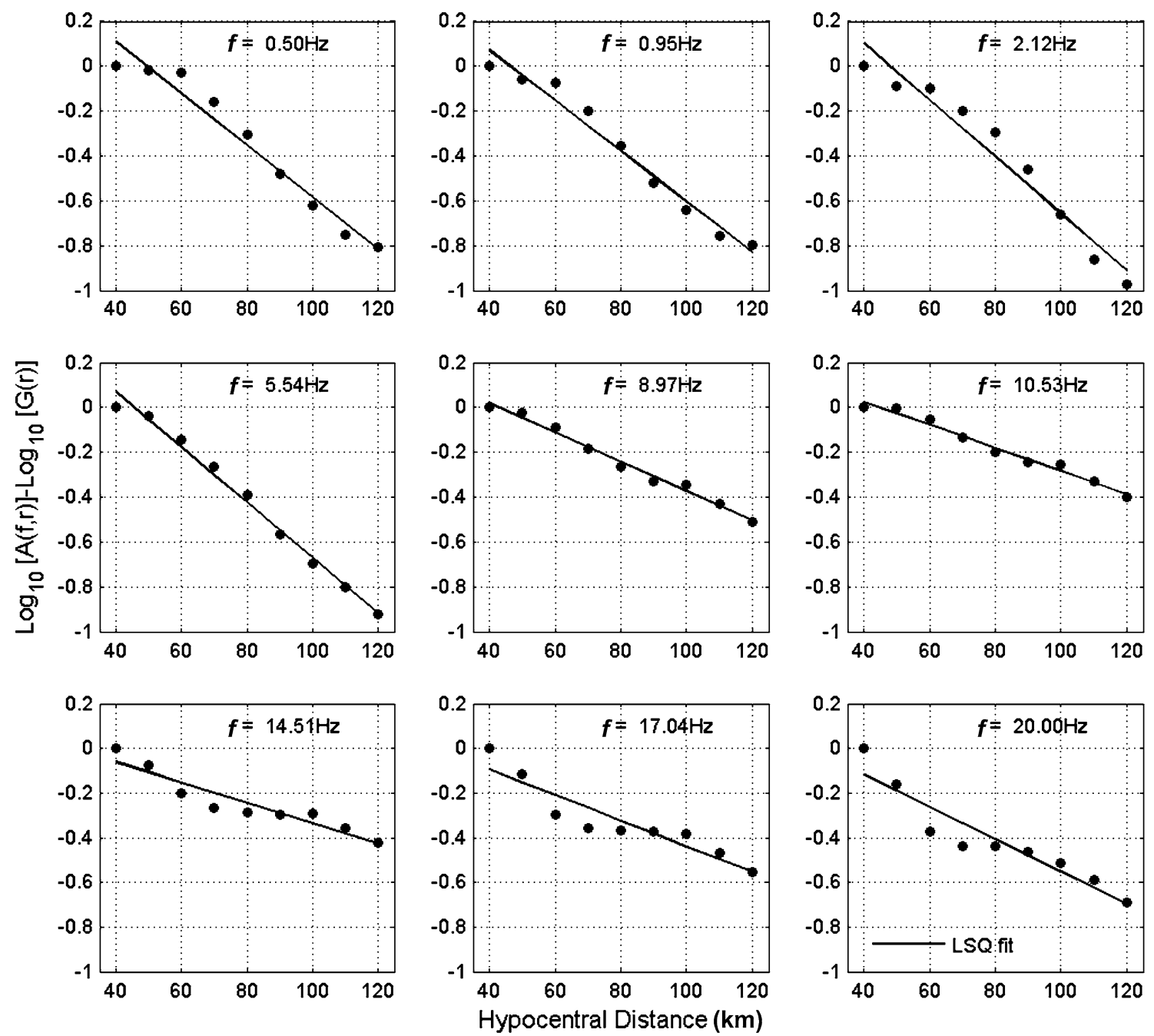

Fig. 8 Attenuation curves corrected for geometrical spreading $\left[\log _{10} A(f, r)-\log _{10} G(r)\right.$ versus $\left.r\right]$ and fitted straight line (least squares fit) at 9 of the 24 frequencies studied

where $a(r)=\log _{10} \hat{A}_{i j}\left(f, r_{i j}\right)-\log _{10} G\left(r_{i j}\right)$ and $m=\{[\pi f r /$ $\left.\left.Q_{\mathrm{s}}(f) \beta\right] \cdot \log _{10}(\mathrm{e})\right\}$. It is important to note that $m$ is the resulting slope of the linear least-squares fit obtained between 40 and $120 \mathrm{~km}$ for each frequency analyzed. Therefore, Eq. (5) takes the following form:

$\log _{10} \hat{A}_{i j}\left(f, r_{i j}\right)-\log _{10} G\left(r_{i j}\right)=-\frac{\pi f}{Q_{\mathrm{s}}(f) \beta} r_{i j} \cdot \log _{10} \mathrm{e}$

It becomes evident that by correcting the attenuation functions for geometrical spreading and plotting versus distance, $Q_{\mathrm{s}}(f)$ can be evaluated from the slope of a linear least-squares fit. Figure 8 shows the attenuation functions corrected for the geometrical spreading and the regression used to estimate $Q_{\mathrm{s}}$ for different frequencies.

A homogeneous attenuation model for the studied region from a linear fit of the determined values of $Q_{\mathrm{s}}$ over the selected frequency band of 0.5 to $20 \mathrm{~Hz}$ takes the form
$Q_{\mathrm{s}}(f)=33 f^{1.22}$ as shown in Fig. 9. The regression error of the fit is shown by vertical error bars and can be significantly reduced by choosing multiple $Q_{\mathrm{s}}$ models over different frequency bands.

\section{Results and discussion}

The obtained NAFs show that in general the attenuation curves are well constrained. At higher frequencies $(f>12 \mathrm{~Hz})$, initially the change in rate of amplitude decay is fast but gradually slows down beyond $70 \mathrm{~km}$ distance. A strong frequency dependence of $Q_{\mathrm{s}}$ is found between the frequency range of $(0.5$ and $20 \mathrm{~Hz})$ and is given by the relation $Q_{\mathrm{s}}(f)=33 f^{1.22}$. Below $6 \mathrm{~Hz}, Q_{\mathrm{s}}$ can be best approximated by $Q_{\mathrm{s}}(f)=36 f^{0.94}$ showing relatively weaker frequency dependence as compared to relation $Q_{\mathrm{s}}$ 


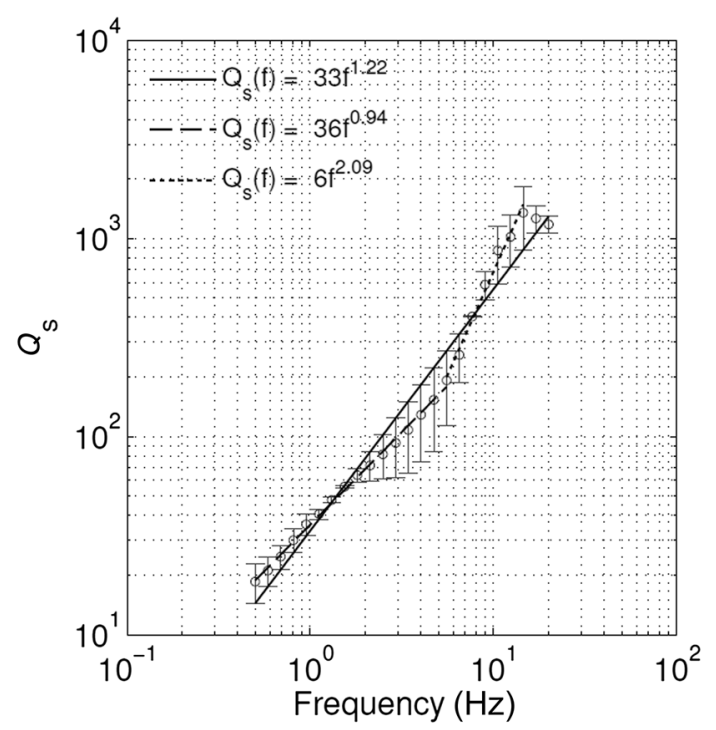

Fig. 9 Estimated $Q_{\mathrm{s}}$-model for Eastern Tohoku obtained from the least square fit of $Q_{\mathrm{s}}$ between 0.5 and $20 \mathrm{~Hz}$

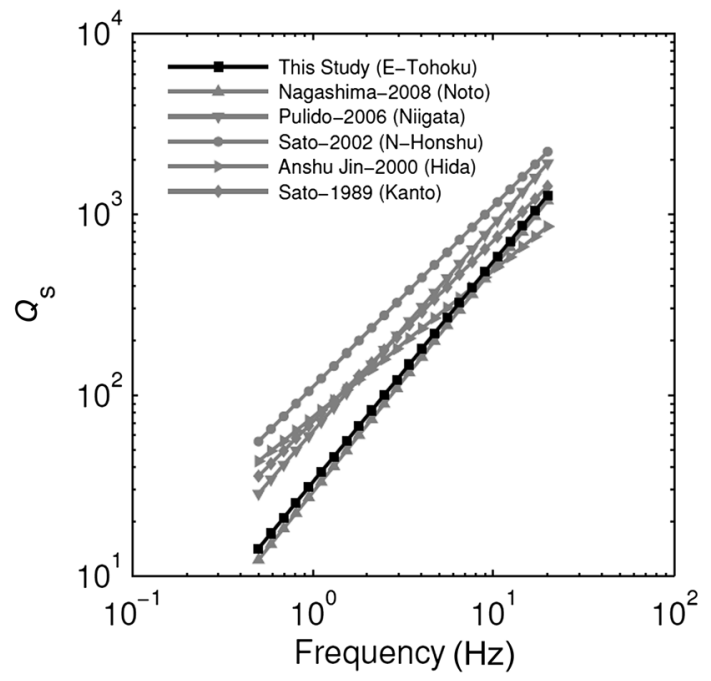

Fig. 10 Comparison of $Q_{\mathrm{s}}$ for crustal earthquakes in Japan

$(f)=6 f^{2.09}$ for the frequency range between 6 and $15 \mathrm{~Hz}$. This change in frequency behaviour of $Q_{\mathrm{s}}$ can be attributed to the localized discontinuities within the crust which are present in the form of faults or densely fractured zones in the region (Umino et al. 1990).

A strong attenuation in Tohoku region is quite obvious, as evident from several past studies. The $Q_{\mathrm{s}}$ estimates found in this study are comparable to those obtained for the
Noto region in Japan (Itoi et al. 2008). Both functions are obtained from the crustal earthquake datasets. The slopes of the functions are quite similar, leading to the determination of almost identical $Q_{\mathrm{s}}(f)$-model as shown in Fig. 10. The derived $Q_{\mathrm{s}}(f)$-model is also comparable to those of crustal earthquakes at other regions in Japan.

\section{Conclusions}

Frequency-dependent seismic quality factor $Q_{\mathrm{s}}(f)$ has been evaluated by applying non-parametric inversion method to crustal earthquakes dataset. A strong attenuation in Eastern Tohoku region has been observed between $(0.5$ and $20 \mathrm{~Hz})$ and is given by the relation $Q_{\mathrm{s}}(f)=33 f^{1.22}$ which is close to the background value in the region. This strong attenuation can be attributed to structural heterogeneities created by large earthquakes in the region. The estimates of $Q_{\mathrm{s}}$ could be further refined by adopting a bilinear $Q_{\mathrm{s}}(f)$-model. The frequency dependence of $Q_{\mathrm{s}}$ in the frequency range between 0.5 and $6 \mathrm{~Hz}$ can be best approximated by $Q_{\mathrm{s}}(f)=36 f^{0.94}$ showing relatively weaker frequency dependence as compared to the relation $Q_{\mathrm{s}}(f)=6 f^{2.09}$ for the frequency range between 6 and $15 \mathrm{~Hz}$. The observed estimates of $Q_{\mathrm{s}}$ could provide basic input for determining source and site parameters (Parolai et al. 2000). Therefore, more realistic estimates of strong ground motion parameters could be obtained for assessment of seismic hazards in the region.

Acknowledgments The study was carried out as a part of author's M.Sc Research under the project: "Strengthening of Earthquake Engineering Center", funded by Higher Education Commission, Government of Pakistan. The data used in this study were downloaded online from K-Net (Kyoshin Network) website: http:// www.kik.bosai.go.jp/, managed under the framework of National Research Institute for Earth Science and Disaster Prevention (NIED). The author wishes to thank Professor Apostolos Papageorgiou for his valuable guidance and support to carry out this research.

Open Access This article is distributed under the terms of the Creative Commons Attribution 4.0 International License (http://crea tivecommons.org/licenses/by/4.0/), which permits unrestricted use, distribution, and reproduction in any medium, provided you give appropriate credit to the original author(s) and the source, provide a link to the Creative Commons license, and indicate if changes were made.

\section{Appendix}

See Table 2. 
Table 2 Earthquake coordinates and hypocentral distances

\begin{tabular}{|c|c|c|c|c|c|c|c|c|c|c|}
\hline $\begin{array}{l}\text { Event } \\
\text { no. }\end{array}$ & $\begin{array}{l}\text { Lat. } \\
\left({ }^{\circ}\right)\end{array}$ & $\begin{array}{l}\text { Long. } \\
\left({ }^{\circ}\right)\end{array}$ & $\begin{array}{l}\text { Depth } \\
(\mathrm{km})\end{array}$ & $M_{\mathrm{w}}$ & $\begin{array}{l}\text { IWT007 } \\
(\mathrm{km})\end{array}$ & $\begin{array}{l}\text { MYG002 } \\
(\mathrm{km})\end{array}$ & $\begin{array}{l}\text { MYG003 } \\
(\mathrm{km})\end{array}$ & $\begin{array}{l}\text { MYG004 } \\
(\mathrm{km})\end{array}$ & $\begin{array}{l}\text { MYG005 } \\
(\mathrm{km})\end{array}$ & $\begin{array}{l}\text { MYG011 } \\
(\mathrm{km})\end{array}$ \\
\hline 1 & 39.025 & 140.910 & 13 & 5.0 & 89.38 & - & 62.70 & 63.14 & 105.21 & 105.21 \\
\hline 2 & 38.456 & 141.160 & 13 & 4.8 & 111.18 & 101.37 & 52.96 & 62.33 & - & - \\
\hline 3 & 38.458 & 141.150 & 14 & 5.0 & 111.92 & - & 53.93 & 62.83 & 56.70 & 56.70 \\
\hline 4 & 38.520 & 141.230 & 11 & 4.4 & 102.00 & 96.09 & 46.31 & 58.82 & - & 53.65 \\
\hline 5 & 38.466 & 141.190 & 12 & 4.4 & 108.90 & 99.50 & 51.04 & 61.42 & - & 53.59 \\
\hline 6 & 38.855 & 142.260 & 18 & 5.1 & 64.57 & 117.45 & 94.98 & 122.56 & - & - \\
\hline 7 & 39.067 & 140.810 & 9 & 4.6 & 94.85 & 113.26 & 67.73 & 64.33 & - & 106.12 \\
\hline 8 & 38.998 & 142.060 & 19 & 3.9 & 46.19 & 113.15 & 85.49 & - & - & - \\
\hline 9 & 39.090 & 140.910 & 13 & 4.6 & 87.74 & - & 66.88 & 67.24 & - & - \\
\hline 10 & 39.142 & 140.940 & 11 & 5.2 & 82.93 & - & 67.69 & 68.95 & - & - \\
\hline 11 & 39.147 & 140.920 & 11 & 4.3 & 84.47 & 113.47 & 68.89 & 69.51 & - & - \\
\hline 12 & 38.995 & 140.890 & 10 & 4.8 & 91.22 & 108.19 & 60.06 & 59.19 & - & 96.22 \\
\hline 13 & 39.010 & 140.940 & 12 & 4.0 & 87.38 & 108.34 & - & 61.09 & - & - \\
\hline 14 & 39.010 & 140.940 & 12 & 4.0 & 95.33 & 111.27 & 63.49 & 61.12 & - & 99.11 \\
\hline 15 & 38.997 & 140.840 & 11 & 5.3 & 83.15 & 112.20 & - & 68.44 & - & - \\
\hline 16 & 39.135 & 140.940 & 11 & 4.6 & 90.04 & 109.62 & 62.47 & 61.58 & - & - \\
\hline 17 & 39.035 & 140.890 & 10 & 4.0 & 98.15 & - & 54.01 & 50.68 & - & - \\
\hline 18 & 38.873 & 140.860 & 6 & 4.1 & 110.07 & - & 67.97 & 60.54 & - & - \\
\hline 19 & 38.903 & 140.700 & 10 & 5.4 & 108.61 & - & 62.93 & 52.58 & - & - \\
\hline 20 & 38.903 & 140.700 & 0 & 4.8 & 122.33 & 119.47 & 73.00 & - & 104.82 & 104.82 \\
\hline 21 & 38.803 & 140.600 & 10 & 5.0 & 88.90 & 109.63 & 61.52 & 61.94 & - & 104.17 \\
\hline 22 & 39.020 & 140.910 & 12 & 4.3 & - & 93.79 & 39.99 & 50.22 & 72.33 & 72.33 \\
\hline 23 & 38.765 & 141.140 & 9 & 4.5 & - & 93.63 & 41.44 & 51.14 & 59.83 & 59.83 \\
\hline 24 & 38.603 & 141.150 & 8 & 4.1 & - & 93.69 & 39.89 & 50.32 & 72.41 & 72.41 \\
\hline 25 & 38.768 & 141.140 & 9 & 4.1 & - & 92.24 & 38.55 & 47.92 & 67.56 & 67.56 \\
\hline 26 & 38.711 & 141.130 & 7 & 4.2 & - & 103.48 & - & - & 50.12 & 50.12 \\
\hline 27 & 38.365 & 141.220 & 13 & 3.5 & - & 101.26 & 53.75 & 62.78 & 53.59 & 53.59 \\
\hline 28 & 38.433 & 141.160 & 12 & 5.5 & - & 102.76 & - & - & 53.18 & 53.18 \\
\hline 29 & 38.400 & 141.150 & 12 & 3.5 & - & 102.23 & - & - & 51.86 & 51.86 \\
\hline 30 & 38.388 & 141.160 & 11 & 3.5 & - & 100.73 & - & 63.17 & 52.60 & 52.60 \\
\hline 31 & 38.433 & 141.190 & 12 & 3.9 & - & 102.55 & - & 64.67 & 52.28 & 52.28 \\
\hline 32 & 38.386 & 141.150 & 11 & 3.9 & - & 101.47 & - & - & 54.66 & 54.66 \\
\hline 33 & 38.458 & 141.190 & 14 & 3.6 & - & 102.61 & 56.76 & 67.17 & 50.96 & 50.96 \\
\hline 34 & 38.390 & 141.210 & 13 & 4.0 & - & 101.15 & - & 61.99 & 56.45 & 56.45 \\
\hline 35 & 38.483 & 141.180 & 14 & 4.0 & - & 100.26 & - & 61.62 & 53.99 & 53.99 \\
\hline 36 & 38.456 & 141.170 & 12 & 4.0 & - & 100.59 & 52.52 & 61.87 & 54.01 & 54.01 \\
\hline 37 & 38.450 & 141.170 & 12 & 4.2 & - & 97.91 & 49.84 & 61.30 & - & - \\
\hline 38 & 38.465 & 141.220 & 11 & 4.1 & - & 100.68 & - & - & 56.28 & 56.28 \\
\hline 39 & 38.481 & 141.160 & 13 & 3.6 & - & 101.16 & - & 62.17 & 55.15 & 55.15 \\
\hline 40 & 38.518 & 141.230 & 10 & 3.5 & - & 95.21 & - & 58.05 & 52.79 & 52.79 \\
\hline 41 & 38.465 & 141.190 & 13 & 3.9 & - & 100.55 & - & 62.24 & 54.51 & 54.51 \\
\hline 42 & 38.483 & 141.130 & 14 & 4.1 & - & 102.24 & 52.76 & 61.32 & 58.35 & 58.35 \\
\hline 43 & 38.513 & 141.220 & 11 & 3.5 & - & 96.33 & - & 59.08 & 53.38 & 53.38 \\
\hline 44 & 38.485 & 141.190 & 12 & 3.8 & - & 98.96 & - & 60.40 & 54.45 & 54.45 \\
\hline 45 & 38.383 & 141.170 & 11 & 3.8 & - & 102.18 & - & 65.17 & 51.26 & 51.26 \\
\hline 46 & 38.381 & 141.190 & 12 & 3.5 & - & 102.63 & - & - & 51.01 & 51.01 \\
\hline
\end{tabular}


Table 2 continued

\begin{tabular}{|c|c|c|c|c|c|c|c|c|c|c|}
\hline $\begin{array}{l}\text { Event } \\
\text { no. }\end{array}$ & $\begin{array}{l}\text { Lat. } \\
\left({ }^{\circ}\right)\end{array}$ & $\begin{array}{l}\text { Long. } \\
\left({ }^{\circ}\right)\end{array}$ & $\begin{array}{l}\text { Depth } \\
(\mathrm{km})\end{array}$ & $M_{\mathrm{w}}$ & $\begin{array}{l}\text { IWT007 } \\
(\mathrm{km})\end{array}$ & $\begin{array}{l}\text { MYG002 } \\
(\mathrm{km})\end{array}$ & $\begin{array}{l}\text { MYG003 } \\
(\mathrm{km})\end{array}$ & $\begin{array}{l}\text { MYG004 } \\
(\mathrm{km})\end{array}$ & $\begin{array}{l}\text { MYG005 } \\
(\mathrm{km})\end{array}$ & $\begin{array}{l}\text { MYG011 } \\
(\mathrm{km})\end{array}$ \\
\hline 47 & 38.466 & 141.160 & 13 & 3.6 & - & 101.23 & - & - & 55.84 & 55.84 \\
\hline 48 & 38.202 & 141.150 & 12 & 4.5 & - & 112.59 & 72.87 & 79.13 & - & - \\
\hline 49 & 38.198 & 141.150 & 12 & 4.5 & - & 112.85 & - & 79.45 & 41.73 & 41.73 \\
\hline 50 & 38.412 & 141.120 & 13 & 4.0 & - & 104.26 & - & 64.18 & 44.38 & 44.38 \\
\hline 51 & 39.102 & 140.870 & 13 & 3.9 & - & 115.26 & 69.29 & 68.55 & - & - \\
\hline 52 & 38.867 & 140.860 & 9 & 4.1 & - & 105.69 & 55.77 & 53.22 & - & - \\
\hline 53 & 38.880 & 140.760 & 7 & 3.9 & - & 109.34 & 61.54 & 54.92 & - & - \\
\hline 54 & 38.908 & 140.760 & 7 & 4.1 & - & 109.97 & 62.55 & 56.02 & - & - \\
\hline 55 & 38.883 & 140.760 & 8 & 4.0 & - & 109.88 & 61.80 & 55.67 & - & - \\
\hline 56 & 39.090 & 140.930 & 11 & 4.2 & - & 110.62 & 64.41 & 65.34 & - & - \\
\hline 57 & 39.038 & 140.860 & 12 & 4.5 & - & 112.37 & 65.10 & 63.81 & - & - \\
\hline 58 & 38.757 & 140.780 & 3 & 4.6 & - & 103.54 & 55.32 & 47.82 & - & - \\
\hline 59 & 38.753 & 140.760 & 3 & 4.6 & - & 104.49 & 56.61 & 48.49 & - & - \\
\hline 60 & 39.103 & 140.840 & 12 & 3.9 & - & 115.78 & 70.24 & 68.40 & - & - \\
\hline 61 & 39.062 & 140.860 & 10 & 4.3 & - & 111.75 & 65.49 & 63.76 & - & - \\
\hline 62 & 38.895 & 140.940 & 8 & 3.9 & - & 101.91 & 51.53 & 51.93 & - & - \\
\hline 63 & 38.500 & 141.200 & 10 & 4.4 & - & 96.35 & 47.10 & 58.22 & 41.25 & 41.25 \\
\hline 64 & 38.286 & 140.760 & 13 & 5.0 & - & 122.82 & 80.21 & 75.77 & 77.62 & 77.62 \\
\hline 65 & 38.270 & 140.760 & 13 & 4.0 & - & 123.54 & - & - & 77.67 & 77.67 \\
\hline 66 & 38.286 & 140.780 & 14 & 3.6 & - & 122.84 & - & - & 77.03 & 77.03 \\
\hline 67 & 38.703 & 141.130 & 8 & 3.7 & - & 93.10 & 39.42 & - & 67.39 & 67.39 \\
\hline 68 & 39.021 & 140.910 & 12 & 3.7 & - & - & 39.94 & 50.27 & 72.33 & 72.33 \\
\hline 69 & 38.766 & 141.140 & 9 & 3.5 & - & - & 49.05 & 60.53 & 52.16 & 52.16 \\
\hline 70 & 38.478 & 141.220 & 11 & 3.9 & - & - & - & 63.64 & 53.96 & 53.96 \\
\hline 71 & 38.436 & 141.180 & 13 & 3.8 & - & - & - & 62.11 & 55.29 & 55.29 \\
\hline 72 & 38.481 & 141.170 & 12 & 3.5 & - & - & - & 60.21 & 55.19 & 55.19 \\
\hline 73 & 38.468 & 141.190 & 12 & 4.0 & - & - & - & 61.31 & 53.67 & 53.67 \\
\hline 74 & 38.446 & 141.190 & 14 & 4.1 & - & - & - & 64.10 & 54.63 & 54.63 \\
\hline 75 & 38.383 & 141.160 & 12 & 3.8 & - & - & - & 65.79 & 52.55 & 52.55 \\
\hline 76 & 38.425 & 141.210 & 11 & 3.7 & - & - & - & 63.35 & 50.41 & 50.41 \\
\hline 77 & 38.428 & 141.190 & 12 & 3.9 & - & - & - & 63.64 & 52.03 & 52.03 \\
\hline 78 & 38.383 & 141.160 & 11 & 3.8 & - & - & - & 65.09 & 51.51 & 51.51 \\
\hline 79 & 38.463 & 141.190 & 12 & 3.9 & - & - & - & 61.58 & 53.47 & 53.47 \\
\hline 80 & 38.496 & 141.180 & 12 & 4.4 & - & - & - & 59.65 & 55.37 & 55.37 \\
\hline 81 & 38.451 & 141.170 & 13 & 3.9 & - & - & - & 62.69 & 54.73 & 54.73 \\
\hline 82 & 38.903 & 140.600 & 10 & 4.3 & - & - & - & 65.02 & 111.15 & 111.15 \\
\hline 83 & 38.903 & 140.700 & 10 & 4.5 & - & - & - & 60.54 & 105.16 & 105.16 \\
\hline 84 & 38.803 & 140.600 & 10 & 4.2 & - & - & - & 62.64 & 104.82 & 104.82 \\
\hline 85 & 38.903 & 140.600 & 10 & 4.3 & - & - & - & 65.02 & 111.15 & 111.15 \\
\hline
\end{tabular}

\section{References}

Andrews D (1986) Objective determination of source parameters and similarity of earthquakes of different size. Earthquake source mechanics, American Geophysical Monograph, Maurice Series 6, vol 37. American Geophysical Union, Washington, DC, pp 259-267
Bindi D, Parolai S, Grosser H, Milkereit C, Karakisa S (2006) Crustal attenuation characteristics in Northwestern Turkey in the range from 1 to $10 \mathrm{~Hz}$. Bull Seismol Soc Am 96:200-214

Castro RR, Anderson JG, Singh SK (1990) Site response, attenuation and source spectra of S-waves along the Guerrero, Mexico, subduction zone. Bull Seismol Soc Am 80:1481-1503 
Itoi T, Nagashima I, Uchiyama Y (2008) Spectral amplitude and phase characteristics of shallow crustal earthquake based on linear inversion of ground motion spectra and some engineering applications. In: The 14th world conference on earthquake engineering, October 12-17, 2008, Beijing, China

Kaminuma K, Aki K (1963) Crustal structure in Japan from the phase velocity of Rayleigh waves, part 2. Bull Earthq Res Inst 42:19-38

Kurahashi S, Irikura K (2011) Source model for generating strong ground motions during the 2011 off the Pacific coast of Tohoku Earthquake. Earth Planets Space 63:571-576

Menke W (1989) Geophysical data analysis: discrete inverse theory. Int. Geophys. Series, vol 45. Academic Press, New York, p 289

Okada Y, Kasahara K, Hori S, Obara K, Sekiguchi S, Fujiwara H, Yamamoto A (2004) Recent progress of seismic observation networks in Japan-Hi-net, F-net, K-NET and KiK-net-. Earth Planets Space 56:xv-xviii

Oth A, Parolai S, Bindi D, Wenzel F (2009) Source spectra and site response from $S$-waves of intermediate-depth Vrancea, Romania, earthquakes. Bull Seismol Soc Am 99:235-254
Oth A, Parolai S, Bindi D (2011) Spectral analysis of K-NET and KiK-net data in Japan. Part I: database compilation and peculiarities. Bull Seismol Soc Am 101(2):652-656

Parolai S, Bindi D, Augliera P (2000) Application of the generalized inversion technique (GIT) to a microzonation study: numerical simulations and comparison with different site-estimation techniques. Bull Seismol Soc Am 90:286-297

Pavlenko OV, Wen KL (2008) Estimation of nonlinear soil behavior during the 1999 Chi-Chi, Taiwan earthquake. Pure Appl Geophys 165:373-407

Smith SW (1999) The Scientist and Engineer's Guide to Digital Signal Processing, 2nd edn. California Technical Publishing, San Diego, pp 277-282

Umino N, Hasegawa A, Takagi A (1990) The relationship between seismicity patterns and fracture zones beneath northeastern Japan. Tohoku Geophys J 33(2):149-162

Zhao D, Horiuchi S, Hasegawa A (1992) Seismic velocity structure of the crust beneath the Japan islands. Tectonophysics 212:289-301 